\title{
A microheater on polyimide substrate for hand-held realtime microfluidic polymerase chain reaction amplification
}

\author{
Dae-Sik Lee ${ }^{{ }^{*}} \mathbb{D}$, Ok Ran $\mathrm{Choi}^{2}$ and Yujin Seo ${ }^{2}$
}

\begin{abstract}
The development of a DNA microfluidic device with a high speed, low power, and low reagent volume is very critical for real-time genotyping and diagnosis in point-of-care applications. This paper reports a polymer-based thermal cycler for a handheld and battery-powered polymerase chain reaction (PCR) system using a polyimide (PI) film-based micro-fabricated heater module and polymer film microfluidic chambers of $10 \mu \mathrm{L}$, with a handheld and low power consumption, compared to state of the art. It took $21 \mathrm{~min}$ for 40 thermal cycling for DNA amplification and a maximum power consumption of $0.6 \mathrm{~W}$. The microheater on PI film substrate fabricated and real-time quantification of deoxyribonucleic acid (DNA) using the heater in hand-held sizes experimentally shown here. The device would be applicable for on-site molecular diagnostics.
\end{abstract}

Keywords: Portable, Polymer-based thermal cycler, Polymerase chain reaction, Molecular diagnostics, Point-of-care testing

\section{Introduction}

The design and fabrication of a DNA microfluidic devices with a high speed, low power, and low reagent volume is very important for real-time genotyping and point-ofcare testing for disease diagnosis $[1,2]$. The work builds on a microfabrication process of the polymer-based heating module reported before [3-7]. At first we had reported a thermal cycler with a polymer chamber and a silicon-based MEMS heater. The device showed a very fast operation and very low power consumption, however, there are problems like fragility, high fabrication cost and low heat capacity of micro-heater [3, 4]. Next, we had developed a thermal cycler with a silicon microchamber and a polymer-based heating module [5-7]. The device showed a reasonably fast operation, low power consumption, and robustness of heaters. Because of excellent thermal conductivity of silicon, the PCR has worked well. However, there are problems like high

\footnotetext{
*Correspondence: dslee@etri.re.kr

${ }^{1}$ Diagnostic \& Therapeutic Systems Research Section, Welfare \& Medical ICT Research Department, Electronics and Telecommunications Research Institute (ETRI), Daejeon, 34129, Republic of Korea

Full list of author information is available at the end of the article
}

fabrication cost and fragility of silicon micro-chambers [5-7]. This time, we have developed a polymer-based thermal cycler, consisting of polymer micro-chambers and the polyimide (PI)- or flexible printed circuit board (FPCB)-based heating modules. Advantage for using PI as a substrate for microheaters is its compatibility with silicon micro fabrication processes with benefits of thermal and chemical endurances, cost effectiveness and clean room fabrication procedures with less instrument usage. Through proper device designing and including integration of double thin metal layers into the polymer heating module for good thermal uniformity, we have successfully implemented a polymer-based thermal cycler [8]. Here, we reported on the design, microfabrication, and experimental results on the polymer-based thermal cycler for a battery-based and real-time DNA amplification system. The method reported here differs from previous works $[3,4]$ in the specific heater materials, [5-7] in the geometry of heating modules and their placement within the microfluidic device structures. 


\section{Design}

The heat distribution in the microchamber was simulated based on buffer solution conditions using CFD-ACE+ simulator (Computational Fluid Dynamics Research Corporation (CFDRC), Alabama, US). In case of heating evenly on surface, we could see that the temperature sustained uniformly in the chamber, as shown in Fig. 1a. The utilized parameters for the simulation bring from the previous report [3]. The system consists of a disposable microfluidic component with a polymer film-based cartridge and a polymer FPCB micro-heating module, a sample-preparation kit, and a miniaturized fluorescence meter. A $100 \mu \mathrm{m}$-thick polymer FPCB film-based microheating modules, integrating a copper film heater, a temperature sensor, and two heat-spreading metal film layers, and the disposable component has five $10 \mu \mathrm{L}$ microfluidic chambers in polycarbonate films, a module combining the heating module and fluidic micro-chamber with a manifold as shown in Fig. $1 \mathrm{~b}-\mathrm{d}$ respectively. The simple, facile, and embedded fluorescence meter using the LEDs and CMOS image sensors, has implemented for quantification of amplicon.

\section{Results and discussion}

A schematic view of the thermal cycler for polymerbased and miniaturized PCR system showed in Fig. 1e, with a close-up detail of the polymer heating modules and placement of all modules in the devices. The pictures of the micro-fabricated heater modules and the $10 \mu \mathrm{L}$-volumed polymer chamber cartridge showed in Fig. 1d. The thermal properties of the heating elements on the polyimide-based film component, including the temperature-consumption power and the time response curve, observed. Top copper resistive lines utilized as a heater and a temperature sensor, respectively. The copper resistance temperature device showed linear relationship between the temperature and resistance for $35-100{ }^{\circ} \mathrm{C}$ and an approximate temperature coefficient of resistance (TCR) of $4400 \mathrm{ppm} / \mathrm{K}$ was determined as shown in Fig. 2a. The initial resistance of heater is $34 \Omega$ and the resistance of the resistance temperature detector (RTD) is $65 \Omega$ in the room temperature. The polymer heating modules shows the heating and cooling rate of about $8{ }^{\circ} \mathrm{C} / \mathrm{s}$ and the low power consumption of about $0.6 \mathrm{~W}$ at each chamber at maximum working temperature of $96^{\circ} \mathrm{C}$ (Fig. 2).

To investigate DNA amplification performances of the thermal cycler, two kinds of DNA sequence, $\beta$-actin, $70 \mathrm{bp}$, one of six different actin isoforms which have been identified in humans; and Cynanchum auriculatum Royle ex Wight (C. auriculatum), $150 \mathrm{bp}$, a species of climbing vine swallowworts) have been utilized. For extraction of DNA, we utilized a laboratory-made kit DNA extraction
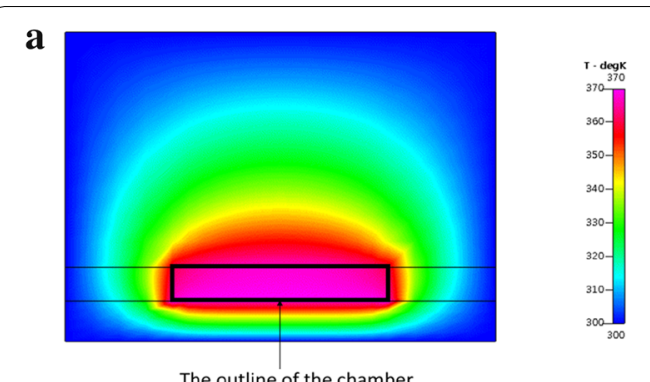

b

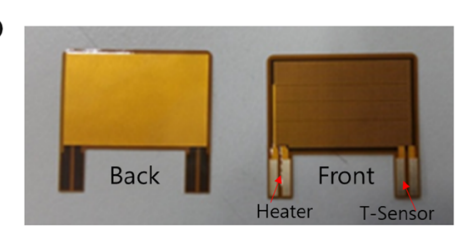

c

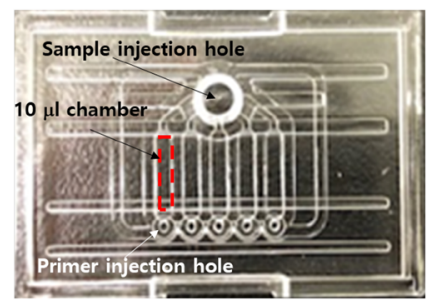

d

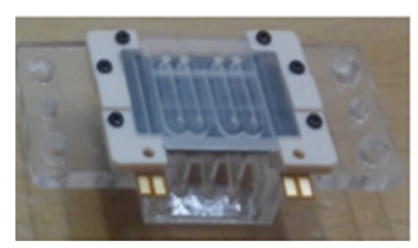

$\mathbf{e}$

CMOS image sensor

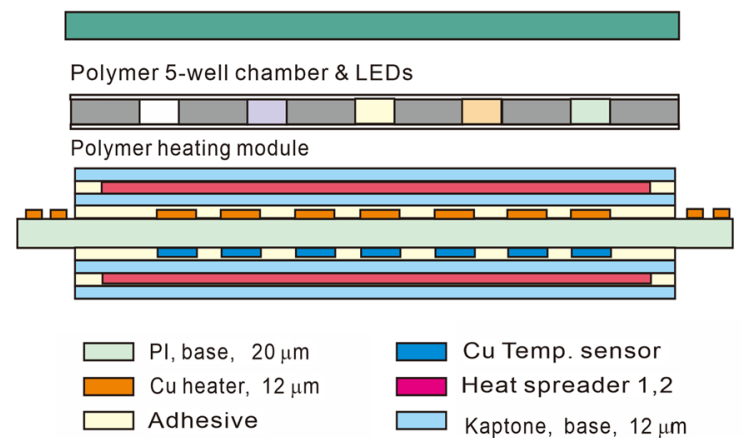

Fig. 1 a Simulated temperature distribution from the midst of the micro-chamber at $97^{\circ} \mathrm{C}$ using a simulator. b Pictures of heating modules on the polyimide substrate, $\mathbf{c}$ disposable polymer microfluidic chamber, and $\mathbf{d}$ a module combining the heating module and fluidic micro-chamber with a manifold. e Simple schematic for the battery-powered real-time PCR device, showing how it combines key components and their sizes

kit. It took about 26 min totally to prepare, amplify and analyze DNA templates consisting of the sample preparation, and amplification and analysis of the DNA 


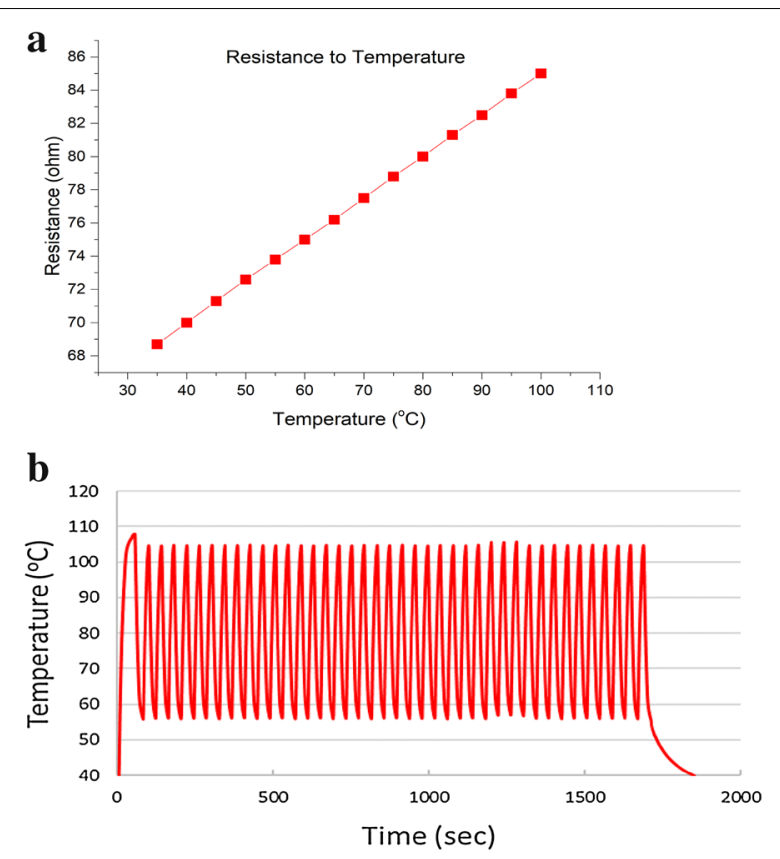

Fig. 2 a Resistance value of the RTD as a function of temperature and $\mathbf{b}$ thermal cycling curves of the microdevice (predenaturization step $99^{\circ} \mathrm{C}, 30 \mathrm{~s}$; denaturization step $99^{\circ} \mathrm{C}, 5 \mathrm{~s}$; annealing step $44^{\circ} \mathrm{C}$, $5 \mathrm{~s}$; extension step $72{ }^{\circ} \mathrm{C}, 0 \mathrm{~s}$ ) with $10 \mu \mathrm{L}$ solution, showing a ramping rate of about $8 \mathrm{~K} / \mathrm{s}$ employing an integrated polyimide-heating device. The maximum power consumption is about $0.6 \mathrm{~W}$ at each chamber at an operating temperature of $99^{\circ} \mathrm{C}$

amplicon. It took about $21 \mathrm{~min}$ for 40 thermal cyclings and a pre-denaturization as shown in Fig. 2b. In order to confirm DNA amplification using the microdevice, the original DNA amplification PCR fluorescence results for $\beta$-actin (amplicon size of 70 base pairs (bp)) genes dying SYBR green 1 before and after 40 amplification cycling were shown in Fig. 3a. We did control the three key temperatures (denaturization, annealing, and extension), sustaining times, and cycling numbers to get optimal working conditions by observing the intensities of Agarose gel electrophoresis band, as shown in Fig. 3b. As results, we determine to be 40 thermal cyclings of $99^{\circ} \mathrm{C}$ for $5 \mathrm{~s}, 44^{\circ} \mathrm{C}$ for $5 \mathrm{~s}$ with a predenatureation step of $99^{\circ} \mathrm{C}$ for $30 \mathrm{~s}$ in three microchambers simultaneously, resulting in getting an excellent DNA amplification results. Furthermore, we have confirmed analysis performance with a high sensitivity $\left(\sim 5 \times 10^{4} / \mathrm{mL}\right)$ and a low detection limit $\left(\sim 5 \times 10^{2}\right.$ copies $)$, as shown in Fig. $3 \mathrm{c}$. It also showed a very high specificity ( 99\%) (not shown here). a
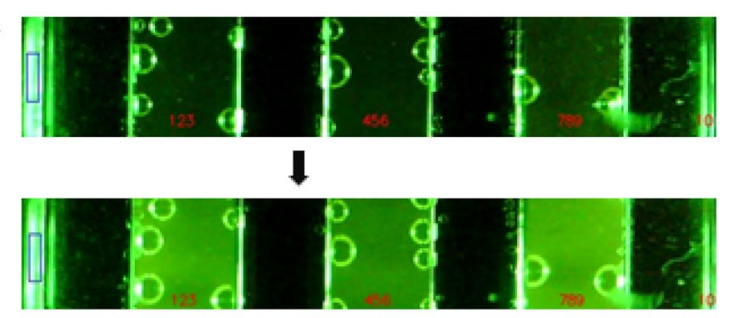

b

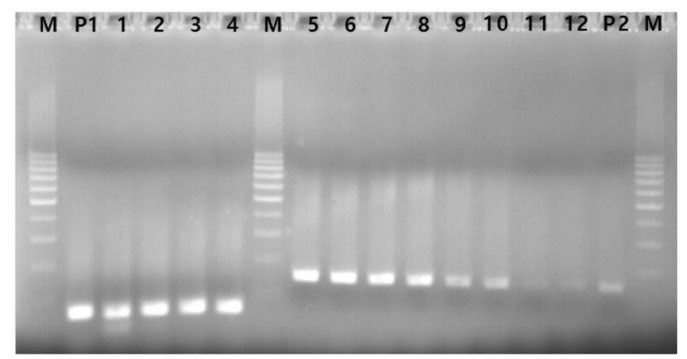

c
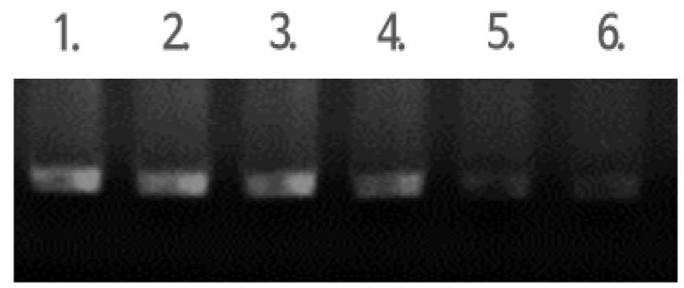

Fig. 3 a The original DNA amplification PCR fluorescence results for $\beta$-actin (amplicon size of 70 bp) genes dying SYBR green 1 before and after 40 amplification cycling in three microchambers si and, $\mathbf{b}$ the Agarose gel electrophoresis results for confirmation of amplification after PCR on the chip for $\beta$-actin (lanes 1-4) and C. auriculatum (amplicon size of 150 bp, lanes 5-12) while controlling the temperatures and sustain time in steps. Here, $M$ lanes are 25 bp marker, $P 1$ is PCR products to $\beta$-actin and P2 is PCR products to Cynanchum auriculatum Royle ex Wight in a commercial thermocycler (UF-150, Genesystem Co., Ltd.) with the same temperature conditions in about $1 \mathrm{~h}$, respectively. c The gel electrophoresis results as a function of starting DNA copies numbers showing the dynamic detection ranges $\left(1.2 \times 10^{7}\right.$ copies, $2.2 \times 10^{6}$ copies, $3.2 \times 10^{5}$ copies, $4.2 \times 10^{4}$ copies, $5.2 \times 10^{3}$ copies, and $6.2 \times 10^{2}$ copies)

\section{Conclusion}

In this study, we demonstrated that the designed and microfabricated microheater on PI film substrate showed the reliable thermal responses throughout forty thermal cyclings. We also demonstrated real-time quantification of DNA of both $\beta$-actin and C. auriculatum using the microheater, successfully through the analysis of the fluorescence and gel electrophoresis results. This device would be applicable to a molecular diagnostics and analysis tool in point-of-care applications. 


\section{Abbreviations}

DNA: deoxyribonucleic acid; PCR: polymerase chain reaction; Pl: polyimyde; FPCB: flexible printed circuit board; LEDs: light-emitting diodes; CMOS: complementary metal oxide semiconductor; TCR: temperature coefficient of resistance; CFDRC: Computational Fluid Dynamics Research Corporation; RTD: resistance temperature detector; bp: base pairs; C. auriculatum: Cynanchum auriculatum Royle ex Wight.

\section{Acknowledgements}

Not applicable.

\section{Authors' contributions}

DS performed the device fabrication, experiments, analyzed the data and wrote the manuscript. OK carried out device characterization. DS and YJ supervised the research and reviewed the manuscript. All authors read and approved the final manuscript.

\section{Funding}

This study was supported by Development of One-step Ultra-Fast Molecular Diagnostics System, the Korean Foundation for Cancer Research (CB-2011-0201), a research project program of Development of a Mobile Diet-monitoring Technology based on multiple biomarkers, the National Research Foundation (NRF) of KOREA (NRF-2017M3A9F1033056), and Ministry of Science and ICT under research company R\&BD project (16AS1410).

\section{Availability of data and materials}

The datasets supporting the conclusions of this article are included within the article.

\section{Competing interests}

The authors declare that they have no competing interests.

\section{Author details}

1 Diagnostic \& Therapeutic Systems Research Section, Welfare \& Medical ICT Research Department, Electronics and Telecommunications Research Institute (ETRI), Daejeon, 34129, Republic of Korea. ${ }^{2}$ Genesystem Co., Ltd., 506, Daejeon
Bioventure Town, 1662, Yuseong-daero, Yuseong-gu, Daejeon, 34054, Republic of Korea.

Received: 5 August 2019 Accepted: 16 October 2019

Published online: 22 October 2019

\section{References}

1. DeMello AJ (2001) DNA amplification: does small really mean efficiengt. Lab Chip 1:24N-29N

2. Ahrberg CD et al (2016) Polymerase chain reaction in microfluidic devices. Lab Chip 16:3866-3884

3. Lee D-S et al (2004) Bulk-micromachined submicroliter-volume PCR chip with very rapid thermal response and low power consumption. Lab Chip 4:401-407

4. Lee D-S et al (2003) Conference: Submicroliter-volume PCR chip with fast thermal response and very low power consumption. MicroTAS 2003:187-190

5. Lee D-S et al (2005) Wafer-scale fabrication of polymer-based microdevices via injection molding and photolithographic micropatterning protocols. Anal Chem 77:5414-5420

6. Lee D-S et al (2005) Conference: Wafer-level fabrication of polymer micro sensors with integrated heat control using novel injection molding and photolithographic micropatterning. Transducers 2005:1284-1287

7. Lee D-S et al (2008) A disposable plastic-silicon micro PCR chip using flexible printed circuit board protocols and its application to genomic DNA amplification. IEEE Sens J 8(5):558-564

8. Lee D-S et al (2019) Conference: A handheld and battery-powered realtime microfluidic polymerase chain reaction (PCR) amplification device. In:Transducers 2019/EUROSENSORS 33th, pp 1063-1066

\section{Publisher's Note}

Springer Nature remains neutral with regard to jurisdictional claims in published maps and institutional affiliations.

\section{Submit your manuscript to a SpringerOpen ${ }^{\circ}$ journal and benefit from:}

- Convenient online submission

- Rigorous peer review

- Open access: articles freely available online

- High visibility within the field

- Retaining the copyright to your article

Submit your next manuscript at $\boldsymbol{\nabla}$ springeropen.com 